\title{
STEREOLOGICAL CHALLENGES WHEN WORKING WITH HEART MUSCLE FIBRES
}

\author{
ANNEMARIE BRÜEL \\ Institute of Anatomy and Stereology and Electron Microscopy Research Laboratory, Wilhelm Meyers Allé, \\ University of Aarhus, 8000-DK C, Denmark \\ e-mail:mb@ana.au.dk \\ (Accepted November 11, 2009)
}

\begin{abstract}
This contribution is based on a series of studies, where stereological methods were applied to hearts from rats treated with growth hormone. A method to estimate the total number of cardiac myocytes is described and, furthermore, length estimates of heart muscle fibres are discussed.
\end{abstract}

Keywords: heart, length, myocytes, number.

\section{INTRODUCTION}

The wall of the heart is composed of three layers: the endocardium, the myocardium, and the pericardium. The myocardium is the main component consisting of cardiac muscle tissue, which is composed of cardiac myocytes, blood vessels, and connective tissue.

The cardiac myocytes are elongated muscle cells with a clear cross-striation. The cells are connected to each other end-to-end through highly specialised regions called the intercalated discs. Some cardiac myocytes may branch at the ends, and thereby join with two or more neighbouring cardiac myocytes. Cardiac myocytes can have one or more nuclei, and the distribution of the number of myocyte nuclei depends on species.

The aim of this paper is to describe a number of stereological estimates and their application and limitations in a rat model of cardiac hypertrophy induced by growth hormone $(\mathrm{GH})$.

\section{MATERIAL AND METHODS SAMPLING AND SECTIONING OF THE HEART}

Female Wistar rats of different ages were treated with GH (Norditropin, Novonordisk, Gentofte, Denmark) for up to 80 days (Table 1). GH was administered subcutaneously in the nape of the neck. The dosage was $5 \mathrm{mg} / \mathrm{kg} /$ day divided into two daily doses given with at least $6 \mathrm{~h}$ interval. The hearts were perfusion- or immersion-fixed in $0.1 \mathrm{M}$ sodium phosphate buffered $4 \%$ formaldehyde $(\mathrm{pH} 7.0)$ (Table $1)$. The left ventricle including septum (LV) was isolated. The wet weight of the LV was determined, and the volume of the $\mathrm{LV}, V(\mathrm{LV})$, was estimated (Méndez and Keys, 1960; Brüel et al., 2002).

The sampling procedure was based on the smooth fractionator principle (Gundersen, 2002). The LV was sectioned into 2-mm-thick slices and sectioned again perpendicular to the slices providing 25-40 small tissue blocks per LV. The tissue blocks were arranged in a smooth fractionator design, and divided into 4 subsets with 6-8 blocks in each subset (Fig. 1).

In order to ensure isotropic orientation of the tissue blocks, they were embedded in isectors, i.e. each tissue block was embedded in agar in rubber moulds with a spherical cavity (Nyengaard and Gundersen, 1992). The isectors were then rolled on the laboratory table until they rested, and in that position embedded in glycolmethacrylate or paraffin. Due to the usage of isectors, isotropic, uniformly random (IUR) sections could be obtained from the tissue blocks.

From the centre of each of the glycolmethacrylate blocks, a $40-\mu \mathrm{m}$-thick and a $2-\mu \mathrm{m}$-thick IUR section were cut on a rotary microtome (Jung 2065 Supercut, Leica Instruments, Nussloch bei Heidelberg, Germany). The 40- $\mu \mathrm{m}$-thick sections were stained with Mayer's haematoxylin and $0.15 \%$ basic fuchsine, and the 2$\mu \mathrm{m}$-thick sections were stained with Mayer's haematoxylin, azocarmine solution, and anilineblue-orange $\mathrm{G}$. From the paraffin blocks $2 \mu \mathrm{m}$ thick serial sections were cut and stained using immunohistochemistry.

Stereological counting equipment is described in Brüel and Nyengaard (2005) and Brüel et al. (2007). 
Table 1. Design of the experiments.

\begin{tabular}{|c|c|c|c|c|}
\hline Study & & Age & Treatment, number and duration & Fixation \\
\hline I & $\begin{array}{l}\text { Brüel A et al. (2002). Growth Horm } \\
\text { IGF Res 12:106-15. }\end{array}$ & 8 months & $\begin{array}{l}\text { Saline }(\mathrm{n}=7), 80 \mathrm{~d} \\
\mathrm{GH}(\mathrm{n}=7), 80 \mathrm{~d}\end{array}$ & immersion \\
\hline II & $\begin{array}{l}\text { Brüel A, Nyengaard JR (2005). } \\
\text { Basic Res Cardiol 100:311-9. }\end{array}$ & 3 months & No treatment $(\mathrm{n}=5)$ & perfusion \\
\hline III & $\begin{array}{l}\text { Brüel A et al. (2005). Growth Horm } \\
\text { IGF Res 15:256-64. }\end{array}$ & 3 months & $\begin{array}{l}\text { Saline }(n=3), 5 d \\
\text { Saline }(n=3), 10 d \\
\text { Saline }(n=3), 20 d \\
\text { Saline }(n=3), 40 d \\
\text { Saline }(n=3), 80 d \\
\text { GH }(n=3), 5 d \\
\text { GH }(n=3), 10 d \\
\text { GH }(n=3), 20 d \\
\text { GH }(n=3), 40 d \\
\text { GH }(n=3), 80 d\end{array}$ & perfusion \\
\hline IV & $\begin{array}{l}\text { Brüel A et al. (2006). Growth Horm } \\
\text { IGF Res 16:193-201. }\end{array}$ & 3 months & $\begin{array}{l}\text { Saline }(n=3), 5 d \\
\text { Saline }(n=3), 10 d \\
\text { Saline }(n=3), 20 d \\
\text { Saline }(n=3), 40 d \\
\text { Saline }(n=3), 80 d \\
\text { GH }(n=3), 5 d \\
\text { GH }(n=3), 10 d \\
\text { GH }(n=3), 20 d \\
\text { GH }(n=3), 40 d \\
\text { GH }(n=3), 80 d\end{array}$ & perfusion \\
\hline $\mathrm{V}$ & $\begin{array}{l}\text { Brüel A et al. (2007). Cardiovasc } \\
\text { Res 76:400-8. }\end{array}$ & 3 months & $\begin{array}{l}\text { Saline }(\mathrm{n}=8), 80 \mathrm{~d} \\
\mathrm{GH}(\mathrm{n}=8), 80 \mathrm{~d}\end{array}$ & perfusion \\
\hline
\end{tabular}
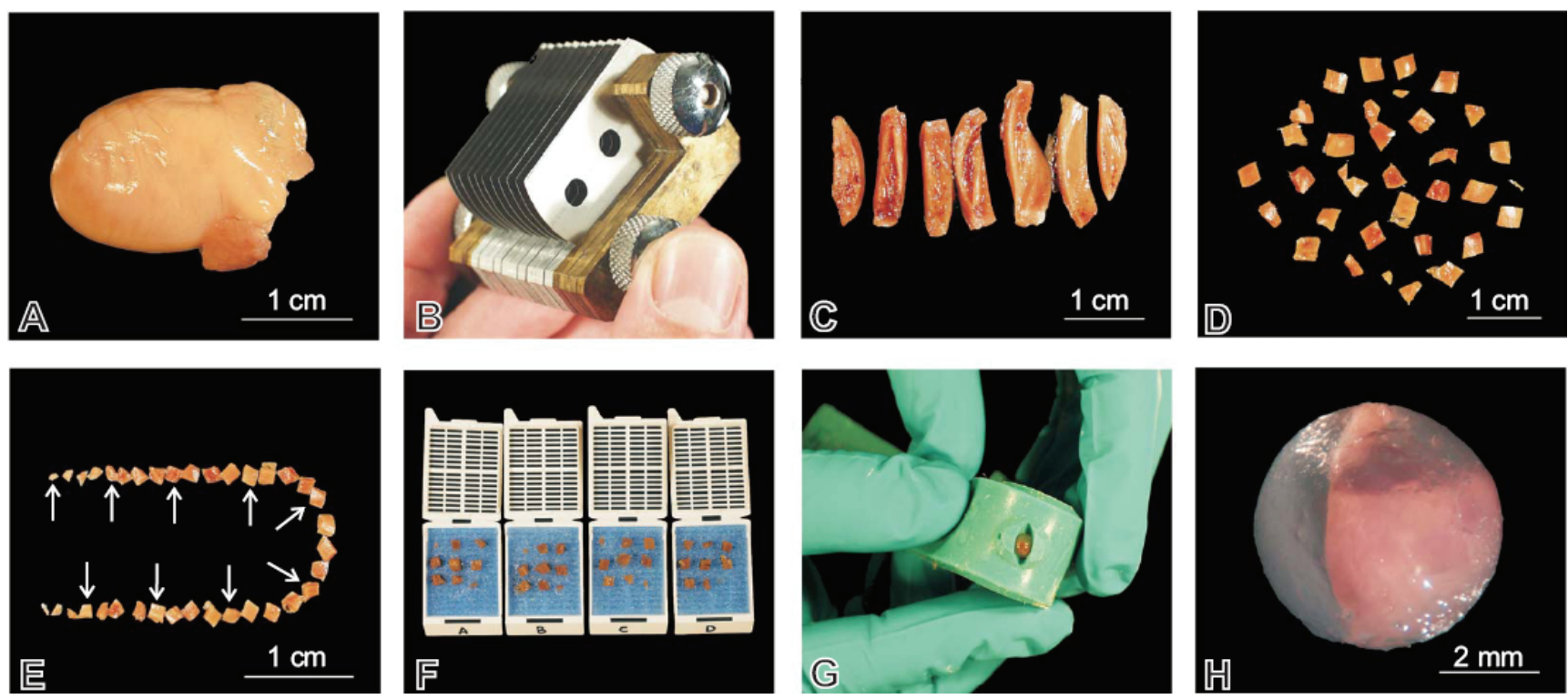

Fig. 1. From the heart (A) LV was isolated. Using a slicing tool (B), LV was sliced once (C), and again, perpendicularly, resulting in 25-40 tissue blocks (D). These were arranged in a smooth fractionator design (E), divided into 4 subsets $(F)$, and then embedded in isectors ( $G$ and H). (Brüel and Nyengaard, 2005). With permission from Springer. 


\section{IMMUNOHISTOCHEMISTRY}

The sections were deparaffinised, and endogenous peroxidase was blocked by $0.5 \% \mathrm{H}_{2} \mathrm{O}_{2}$ in absolute methanol. In order to reveal antigens, the sections were boiled in a microwave oven for $10 \mathrm{~min}$ in 0.1 mM TRIS and 0.5 mM EGTA, pH 9. Non-specific binding was blocked by $1 \%$ BSA (bovine serum albumin). The sections were incubated overnight at $4{ }^{\circ} \mathrm{C}$ with the primary antibodies (anti-cadherin: 1:5000, pan, C1821, Sigma-Aldrich, Denmark, anticollagen type IV: 1:100, 68124, ICN Biomedicals Inc., USA) diluted in PBS supplemented with $0.1 \%$ BSA and $0.3 \%$ Triton-X100. Negative control sections were incubated with either mouse or rabbit serum. After washing, the sections were incubated with horseradish peroxidase-conjugated secondary antibodies for $30 \mathrm{~min}$ at $20^{\circ} \mathrm{C}$. The peroxidase stain was visualised by $0.05 \% \quad 3,3$ '-diaminobenzidine tetrahydrochloride dissolved in PBS with $0.1 \% \mathrm{H}_{2} \mathrm{O}_{2}$, and the sections were counterstained with Mayer's haematoxylin, and - if relevant - eosin (Brüel and Nyengaard, 2005).

\section{TISSUE SHRINKAGE}

Tissue shrinkage occurs, when the tissue is being processed, and may influence both densities and total estimates. To estimate shrinkage tissue blocks were weighed, and the wet weight transformed into a volume using a density of $1.06 \mathrm{~g} / \mathrm{cm}^{3}$ (Brüel et al., 2002). The tissue blocks were then embedded in glycolmethacrylate or paraffin, and cut serially in 3 $\mu \mathrm{m}$ thick sections. Using the principle of Cavalieri, the volume of the embedded tissue blocks was estimated. The shrinkage was estimated as the ratio of the volume of tissue blocks before and after tissue processing. In general, global shrinkage of cardiac tissue embedded in glycolmethacrylate was approximately $\pm 5 \%$ on a volume basis. No corrections for shrinkage were made for estimates derived from tissue embedded in glycolmethacrylate as the shrinkage in the individual experiments did not differ statistically from 0 . In contrast, global shrinkage of cardiac tissue embedded in paraffin was 35\% (Brüel et al., 2007), and estimates derived from tissue embedded in paraffin were consequently corrected for shrinkage when appropriate.

\section{NUMERICAL DENSITY AND TOTAL NUMBER OF MYOCYTE NUCLEI}

The numerical density of myocyte nuclei in the $\mathrm{LV}, N_{\zeta}$ (myocyte nuclei/LV), was estimated in the
40- $\mu$ m-thick sections using the optical disector principle (Gundersen, 1986). A nucleus was defined as a myocyte nucleus, if it was located inside a myocyte.

An unbiased counting frame was used to estimate the numerical density of the nuclei (Gundersen, 1977). The sampling volume was the area of the counting frame multiplied by the distance between the first and the last optical sections, which was obtained from the electronic microcator. In order to establish a "guard height" in the $40-\mu \mathrm{m}$-thick sections, each sampling volume was started $5 \mu \mathrm{m}$ below the upper surface of the section. The microscope was focused down through the sampling volume, and a nucleus was counted when it was within the sampling volume and did not touch any of the exclusion lines of the counting frame. Nuclei in focus at the first optical section were not counted. The nuclei were sampled in 15-18 fields of view per tissue block. Using the four corners of the test frame, a reference space was estimated from the points falling on the ventricular tissue. The actual counting took place at a final magnification of $\times 1895$. The distribution of myocyte nuclei through part of the $40-\mu \mathrm{m}$-thick sections ( $z$-axis distribution) was found to be approximately uniform (Fig. 2).

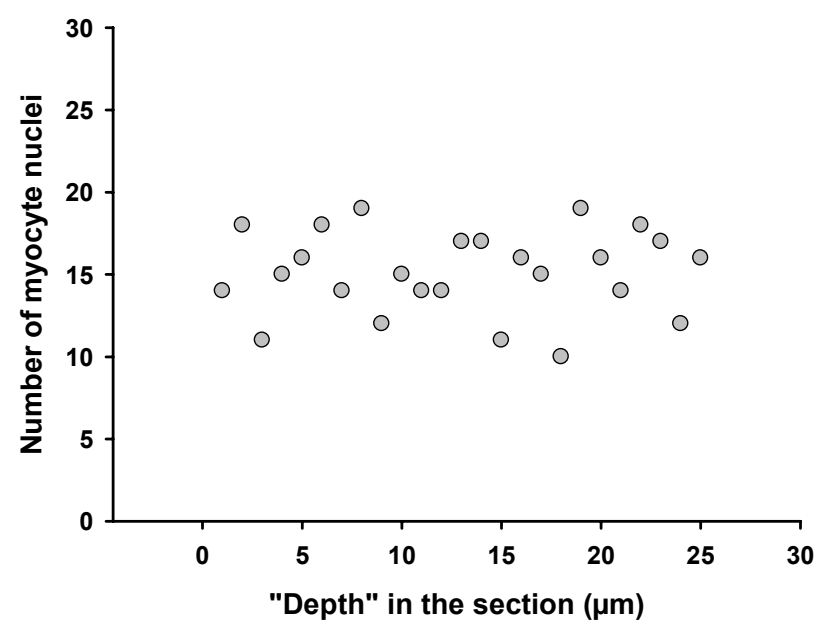

Fig. 2. Distribution of myocyte nuclei through part of a 40- $\mu m$-thick section (z-axis distribution), $n=378$.

The numerical density of myocyte nuclei in the LV, $N_{\nu}$ (myocyte nuclei/LV), was obtained from Eq. 1: 


$$
N_{V}(\text { myocytenuclei/LV }):=\frac{\frac{\sum\left(t_{i} \cdot q_{i}^{-}(\text {myocytenuclei })\right)}{\sum\left(q_{i}^{-}(\text {myocytenuclei })\right)}}{M A} \cdot \frac{\sum Q^{-}(\text {myocytenuclei })}{\sum P(\mathrm{LV})} \cdot\left[\frac{p}{h \cdot a(\text { frame })}\right],
$$

where $t_{i}$ is the local height of the section, where a number of myocyte nuclei, $q_{i}^{-}$(myocyte nuclei), are sampled in the $i^{\prime}$ th field of view, $M A$ is the microtome advance, $\Sigma Q^{-}$(myocyte nuclei) is the total number of myocyte nuclei counted in all disectors of one LV $\Sigma P(\mathrm{LV})$ is the total number of points falling on ventricular tissue (the reference space), $p$ is the number of points that was used to count the points hitting the reference space (here 4 ), $h$ is the height of the disector, i.e. the distance between the first and the last optical section (here $15 \mu \mathrm{m}$ ), and $a$ (frame) is the area of the counting frame. The first term of Eq. 1 corrects for local changes in section thickness.

The total number of myocyte nuclei per LV, $N$ (myocyte nuclei, LV), was estimated by multiplying the numerical density by $V(\mathrm{LV})$.
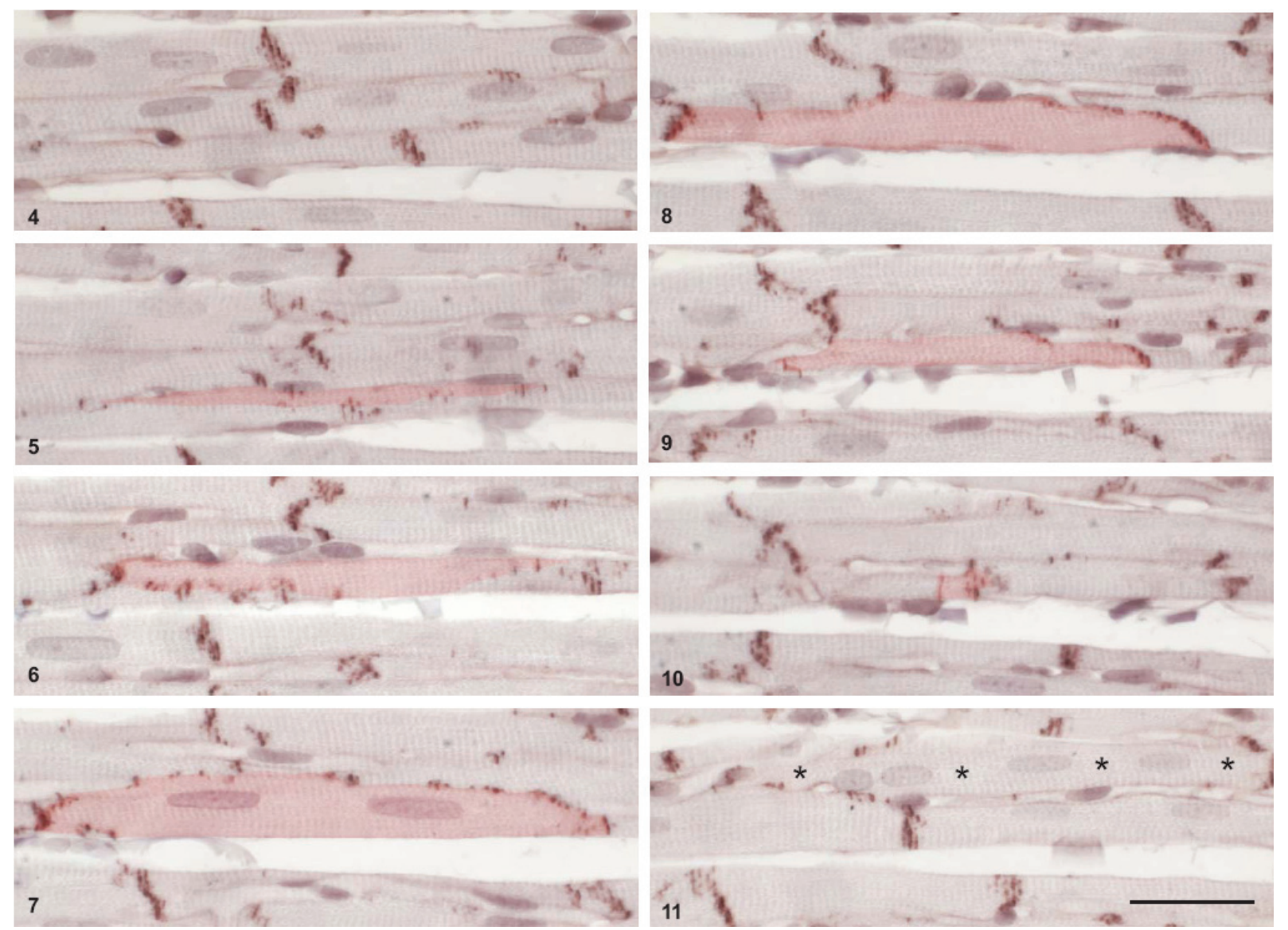

Fig. 3. Sections 4-11 out of 16 serial sections are shown. The sections are stained with antibodies against cadherin and type IV collagen in order to visualise the intercalated discs and the lateral borders (both brown). A binuclear myocyte (marked in transparent red) is followed through the sections. Note the myocyte in section 11 with four nuclei (asterisks). Bar: $30 \mu \mathrm{m}$. (Brüel and Nyengaard, 2005). With permission from Springer. 
Due to the isotropic embedding of the tissue blocks, so-called vertical windows in the sections could be defined as areas of the sections, where the myocytes were cut longitudinally (Baddeley et al., 1986). In such areas, the myocytes had a clear and distinct cross-striation. Only in these vertical windows, fields of view were sampled using systematic uniformly random sampling (SURS). Note that the preferred sampling of longitudinally cut myocytes only provides a uniform sample of myocytes if the sections are isotropic (because it is only in isotropic sections, that all orientations occur with equal likelihood).

The myocytes were sampled by the physical disector using the myocyte nuclei as the counting unit (Sterio, 1984). An unbiased counting frame was used to sample the nuclei. The two central tissue sections 7 and 8 were chosen as reference section and "look-up" section, respectively. Myocytes with nuclei present in the reference section and absent in the "look-up" section, and where the nuclei did not touch the exclusion lines, were sampled.

All myocytes were followed in both directions until they disappeared (at a magnification of $\times 749$ ), and the number of nuclei per myocyte was counted (Jack et al., 1990), as shown in Fig. 3. It is important to notice that if a myocyte had more than one nucleus, the myocyte was sampled as many times as its number of nuclei were present in the physical disector. For each animal, 3 different tissue blocks were analysed, giving a total sample of more than 75 myocytes per animal.

As the myocytes were sampled on the basis of their nuclei, myocytes with two or more nuclei had a larger probability of being sampled than myocytes with only one nucleus. In order to correct for this difference in sampling probability, the number of mononucleated myocytes was divided by 1 , the number of binucleated myocytes was divided by 2 , etc.

The average number of nuclei per myocyte, $\bar{N}_{N}$ (nuclei/myocyte), was obtained from Eq. 2:

$$
\begin{aligned}
& \bar{N}_{N}(\text { nuclei/myocyte }):= \\
& =\frac{\sum\left[Q^{-} \text {(mono) }+Q^{-} \text {(bi) }+Q^{-} \text {(tri) }+Q^{-} \text {(tetra) }\right]}{\frac{\left.\sum Q^{-} \text {(mono }\right)}{1}+\frac{\sum Q^{-}(\text {bi })}{2}+\frac{\sum Q^{-} \text {(tri) }}{3}+\frac{\sum Q^{-} \text {(tetra) }}{4}},
\end{aligned}
$$

where $Q^{-}$(mono) is the number of myocytes with one nucleus in each tissue block, $Q^{-}$(bi) is the number of myocytes with two nuclei in each tissue block, $Q^{-}$(tri) is the number of myocytes with three nuclei in each tissue block, and $Q^{-}$(tetra) is the number of myocytes.

\section{TOTAL NUMBER OF MYOCYTES}

The total number of myocytes in the left ventricle was estimated from:

$$
N(\text { myocytes }, \mathrm{LV}):=\frac{N(\text { myocytenuclei, } \mathrm{LV})}{\left.N_{N} \text { (nuclei/myocyte }\right)} .
$$

\section{VOLUME DENSITIES AND TOTAL VOLUMES}

The volume density of a given structure in the left ventricle, $V_{V}($ structure/LV), was estimated from:

$$
V_{V}(\text { structure/LV }):=\frac{\sum P(\text { structure })}{\sum P(\mathrm{LV})} .
$$

\section{LENGTH DENSITIES AND TOTAL LENGTH}

The length density of the myocytes of the left ventricle, $L_{V}$ (myocyte/LV), was estimated as:

$$
L_{V}(\text { myocyte/LV }):=2 \cdot \frac{\sum Q(\text { myocyte })}{\sum P(\mathrm{LV})} \cdot\left[\frac{p}{a(\text { frame })}\right],
$$

where $\Sigma Q$ (myocyte) denotes the total number of myocyte or capillary profiles of the left ventricle that were counted in an unbiased 2-dimensional counting frame. $\Sigma P(\mathrm{LV})$ is the total number of points hitting the left ventricle (the reference space) and $p$ is the number of points used to count the points hitting on the reference space (Weibel, 1979).

The mean cross sectional area (CSA) of myocytes, $\bar{a}$ (myocyte), was calculated from the following equation:

$$
\bar{a}(\text { myocyte }):=\frac{V_{V}(\text { myocyte } / \mathrm{LV})}{L_{V}(\text { myocyte } / \mathrm{LV})} .
$$

The total length, $L$ (myocyte,LV), and total surface area, $S$ (myocyte,LV), were estimated by multiplying the length and surface densities by $V(\mathrm{LV})$.

\section{VARIATIONS AND MEAN COUNTS}

The coefficients of variation and the average count per animal are given in Table 2. The total variation $\left(\mathrm{CV}_{\text {tot }}\right)$ is calculated as the $\mathrm{SD}$ divided by the mean. The coefficient of error $\left(\mathrm{CE}_{\mathrm{met}}\right)$ is the error variance of the stereological methods and is based on the assumption that the estimates are ratio estimates (Kroustrup and Gundersen, 1983). From the $\mathrm{CV}_{\text {tot }}$ and $\mathrm{CE}_{\text {met, }}$ the biological variation, $\mathrm{CV}_{\text {bio, }}$ can be determined: 


$$
\mathrm{CV}_{\text {bio }}=\sqrt{\mathrm{CV}_{\text {tot }}^{2}-\mathrm{CE}_{\text {met }}^{2}} \text {. }
$$

Table 2. Range of estimates of coefficients of variation and average count per animal (papers $I-V$ ).

\begin{tabular}{lccc}
\hline & $\mathrm{CV}_{\text {tot }}$ & $\mathrm{CV}_{\text {bio }}$ & $\mathrm{CE}_{\text {met }}$ \\
\hline$N($ myocyte nuclei, LV $)$ & $9-14 \%$ & $7-12 \%$ & $6-10 \%$ \\
$N_{N}$ (nuclei/myocyte $)$ & $3 \%$ & $2 \%$ & $1-2 \%$ \\
$N($ myocyte, $\mathrm{LV})$ & $9-12 \%$ & $7 \%$ & $7-9 \%$ \\
$V($ myocyte, $\mathrm{LV})$ & $8-12 \%$ & $8-12 \%$ & $1-2 \%$ \\
$V($ conn. tiss., $\mathrm{LV})$ & $15-27 \%$ & $10-25 \%$ & $10-13 \%$ \\
$V($ capillaries, $\mathrm{LV})$ & $12-24 \%$ & $21-22 \%$ & $10-12 \%$ \\
$L$ (myocyte, LV) & $19-24 \%$ & $3-14 \%$ & $14-19 \%$ \\
\hline
\end{tabular}

\section{RESULTS}

\section{VOLUME OF MYOCYTES, CAPILLARIES AND CONNECTIVE TISSUE}

The total volumes of myocytes (GH: $0.76 \pm 0.08$ $\mathrm{cm}^{3}$ (mean $\pm \mathrm{SD}$ ), control: $0.44 \pm 0.01 \mathrm{~cm}^{3}, P<$ 0.01 ), capillaries (GH: $0.042 \pm 0.005 \mathrm{~cm}^{3}$, control: $0.022 \pm 0.004 \mathrm{~cm}^{3}, P<0.01$ ), and connective tissue (GH: $0.057 \pm 0.012 \mathrm{~cm}^{3}$, control: $0.034 \pm 0.004 \mathrm{~cm}^{3}$, $P<0.05)$ were significantly increased after 80 days of $\mathrm{GH}$ treatment, and these increases were significantly time-dependent (Brüel et al., 2005; Brüel et al., 2006). No differences were found concerning the relative volumes of myocytes, capillaries or connective tissue.

\section{LENGTH DENSITY, TOTAL LENGTH, MEAN VOLUME AND CROSS- SECTIONAL AREA OF MYOCYTES}

GH significantly increased the total myocyte length, and this increase was significantly timedependent. However, the total myocyte length differed between the individual studies. Thus, in the control rats, the total LV myocyte length was: 1.09 $\mathrm{km}$ in paper I (Brüel et al., 2002), $1.40 \mathrm{~km}$ in paper III (Brüel et al., 2005), and $1.83 \mathrm{~km}$ in paper V (Brüel et al., 2007), respectively.

The cross-sectional area (CSA) was not influenced by GH treatment, but varied between the individual studies. In the control rats, the CSA was $467 \mu^{2}$ in paper I (Brüel et al., 2002), $322 \mu \mathrm{m}^{2}$ in paper III (Brüel et al., 2005), and $281 \mu \mathrm{m}^{2}$ in paper V (Brüel et al., 2007), respectively.

\section{NUMERICAL DENSITY AND TOTAL NUMBER OF MYOCYTE NUCLEI}

GH significantly decreased the numerical density of myocyte nuclei after 80 days of treatment. However, GH treatment significantly increased the total number of myocyte nuclei. The GH-induced changes in the numerical density and total number of myocyte nuclei were significantly correlated with time (Fig. 4).

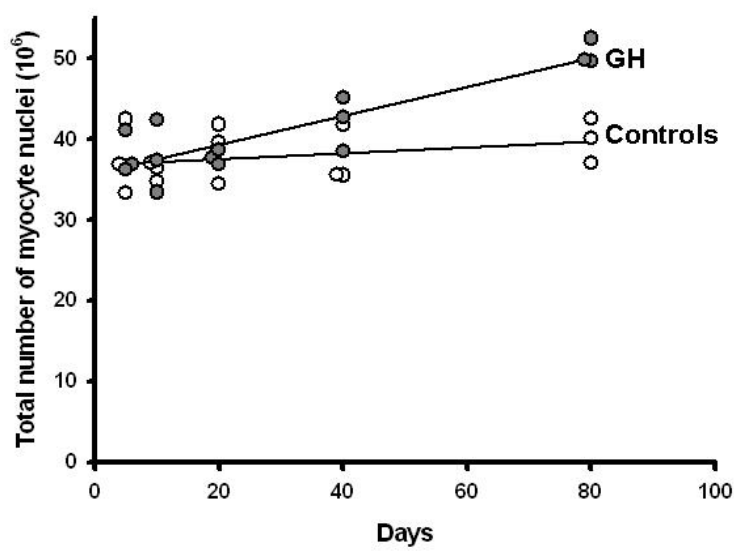

Fig. 4. The total number of myocyte nuclei in $L V$ as a function of time in GH-treated and control rats. Controls: white circles $(r=0.30, N S), G H$ : grey circles ( $r=0.88, P<0.001)$. (Brüel et al., 2005). With permission from Elsevier.

\section{AVERAGE NUMBER OF NUCLEI PER MYOCYTE AND TOTAL NUMBER OF MYOCYTES}

The mean number of myocyte nuclei was 1.75 1.85 per myocyte, and GH treatment did not influence this parameter (Fig. 5).

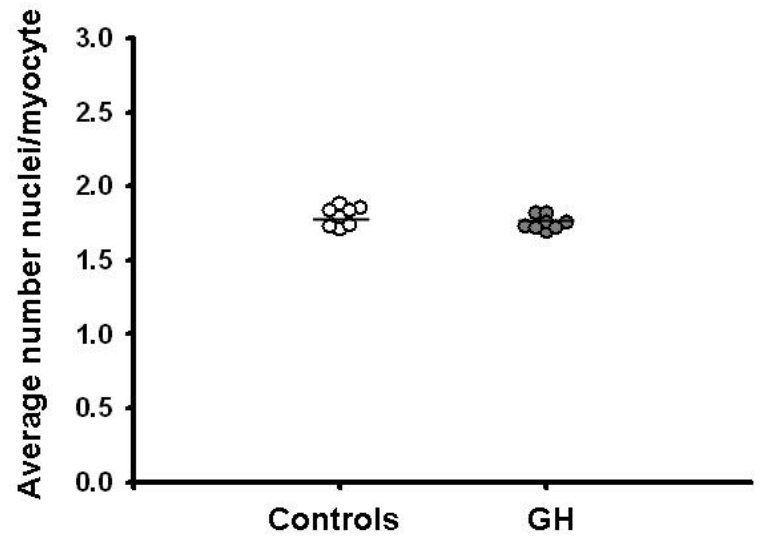

Fig. 5. The effect of 80 days of GH treatment on the average number of nuclei per myocyte. Controls: white circles, GH: grey circles. Bar: mean. (Brüel et al., 2007). With permission from Elsevier. 
GH treatment significantly increased the total number of myocytes in the LV by $33 \%$ (from $19.3 \times 10^{6}$ in the controls to $25.7 \times 10^{6}$ in the GHtreated rats) (Fig. 6).

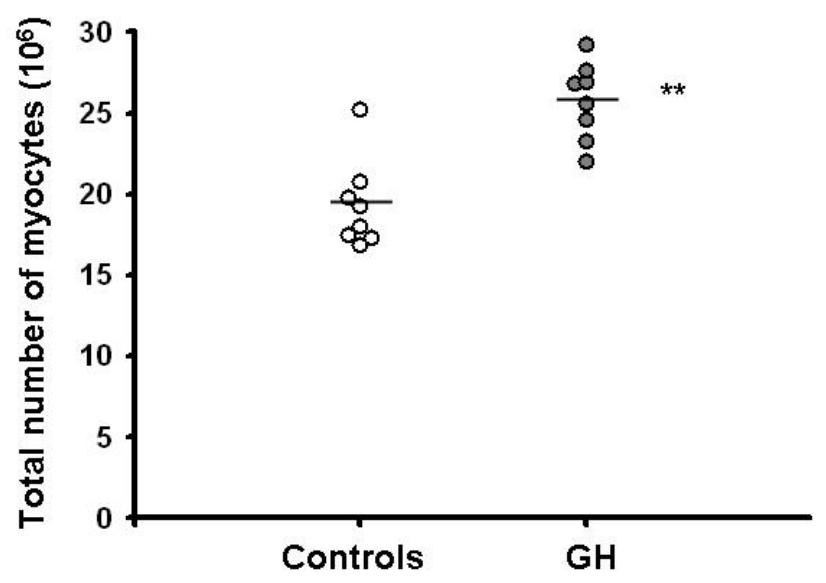

Fig. 6. The effect of 80 days of GH treatment on the total number of myocytes. Controls: white circles, GH: grey circles. Bar: mean. **: $P<0.01$. (Brüel et al., 2007). With permission from Elsevier.

\section{DISCUSSION}

By the use of unbiased stereology it is shown, that GH treatment causes a substantial increase in the total volume of myocytes, capillaries, and connective tissue. However, the relative volume of these structures was not influenced by GH. This indicates that GH induces a proportional and "physiological" growth of the rat myocardium.

GH induced a significantly increase in total length of the cardiac myocytes. However, the total length of the cardiac myocytes of the control animals varied considerably. This variation may be due to differences in the tissue fixation. In I (Brüel et al., 2002), the cardiac tissue was immersion-fixed, whereas in III and V (Brüel et al., 2005; Brüel et al., 2007), the tissue was perfusion-fixed (Table 1). Perfusion-fixation was performed through the heart at a pressure of $140 \mathrm{mmHg}$ resulting in a certain degree of distension of the myocardial tissue. Therefore, it is possible that the myocytes were fixed in a more stretched position during perfusion-fixation than during immersion-fixation, where no pressure is applied. Furthermore, at times, it may be difficult to define the borders of the myocytes. If some myocyte borders were not identified, both the length density and the total length will be underestimated. In V (Brüel et al., 2007), the estimation of the length density was performed on paraffin sections that were immunostained for type IV collagen and cadherin, in order to visualise the myocyte borders more clearly. This enhancement of the cell border demarcation may explain the difference in the total length found in III (Brüel et al., 2005) and V (Brüel et al., 2007).

The CSA was not influenced by GH, but varied between the individual studies (I, III and V). These differences in CSA could be due to differences in fixation and staining as described above (the CSA is estimated as the volume density divided by the length density). Furthermore, the rats in I (Brüel et al., 2002) were 11 months old, whereas the rats in III (Brüel et al., 2005) and V (Brüel et al., 2007) were 6 months old, and the CSA have been shown to increase with age (Raya et al., 1997).

Based on the assumption that cardiac myocytes are shaped as cylinders, the myocyte diameter can be determined from the CSA (which is determined stereologically). In a pilot study the mean diameter was measured "manually" (mean diameter was measured on cross-sections including a nuclear profile of the individual cardiac myocytes in histological sections at $\times 1577)$ and estimated stereologically from the CSA in both plastic sections and paraffin sections immunostained for cadherin and type IV collagen. The myocyte diameters determined from paraffin sections were corrected for shrinkage. The mean myocyte diameters measured "manually" are in accordance with each other and also with the mean diameter estimated stereologically in paraffin sections. The mean myocyte diameter appeared to be slightly higher when estimated stereologically in plastic sections than in paraffin sections, however this difference was not significant (Table 3).

Table 3. Mean myocyte diameter measured "manually" and estimated stereologically in plastic and paraffin sections.

\begin{tabular}{lcccc}
\hline & \multicolumn{2}{c}{ Measured "manually" } & \multicolumn{2}{c}{ Estimated stereologically } \\
\hline & Plastic sections & Paraffin sections & Plastic sections & Paraffin sections \\
& $(n=5)$ & $(n=5)$ & $(n=5)$ & $(n=5)$ \\
\hline Mean diameter $(\mu \mathrm{m})$ & 20.08 & 19.45 & 22.28 & 19.93 \\
CV & 0.09 & 0.07 & 0.20 & 0.08 \\
\hline
\end{tabular}


Previously, it has not been possible to count the total number of cardiac myocytes directly in ordinary histological sections. The reason for this is, that it is difficult to identify the intercalated discs and, also at times, to identify the lateral borders of the myocytes. However, by the use of antibodies against cadherin and type IV collagen the boundaries of the myocytes can be visualised. Subsequently, the mean number of nuclei per myocyte can be estimated in local vertical windows in thin serial sections. Finally, the total number of myocytes can be estimated by dividing the total number of myocyte nuclei by the mean number of nuclei per myocyte. By the use of this method it is shown, that GH increased the total number of cardiac myocytes by $33 \%$.

A simple way to count the myocytes would be to use the optical disector. However, in several pilot studies it was established that the penetration thickness of the antibodies was only 5-15 $\mu \mathrm{m}$, and therefore they did not sufficiently penetrate the 40$\mu \mathrm{m}$-thick sections used with the optical disector. Physical disectors avoid the use of thick sections, but it turned out that it was not possible to use physical disectors, due to difficulties in defining precisely when a myocyte appeared in a light microscopical section. Therefore, serial sections were used instead. Due to the aforementioned problems in defining the precise appearance of a myocyte in the sections, the myocytes had to be sampled on basis of the myocyte nuclei instead of the myocyte itself. As the number of nuclei of the individual myocytes varied, myocytes with two or more nuclei had a higher probability of being sampled than myocytes with only one nucleus. Therefore, corrections for this difference in sampling probability were made (Brüel and Nyengaard, 2005).

The variation of mean number of nuclei per myocyte was $3 \%$, which is surprisingly low. This may indicate that the mean number of myocyte nuclei is important, and therefore under strict control. Interestingly, GH treatment did not influence the mean number of myocyte nuclei per myocyte.

In conclusion, using stereological methods it was shown that GH increased the total volumes of myocytes, connective tissue and capillaries. This was accompanied by a similar increase in the total length of the myocytes. The total number of myocytes was increased by GH treatment indicating that cardiac myocytes may re-enter the cell cycle and divide. Furthermore, length estimates may be influenced by different fixation methods and tissue staining.

\section{ACKNOWLEDGEMENTS}

The presented studies have been supported by The Aarhus University Research Foundation, Bønlykke Foundation, The Danish Health Research Council, The Danish Heart Association, Eva and Henry Frænkels Mindefond, The Foundation of 17. 12. 1981, Kong Christian den Tiendes Foundation, Ingeniør A. F. Wedell Erichsens Legat, Lægevidenskabens Fremme Foundation, Musikforlæggerne Agnes og Knut Mørk Foundation, and P. Carl Pedersens Foundation. Recombinant growth hormone was kindly donated by Novo Nordisk A/S.

\section{REFERENCES}

Baddeley AJ, Gundersen HJG, Cruz-Orive LM (1986). Estimation of surface area from vertical sections. J Microsc 142:259-76.

Brüel A, Christoffersen TE, Nyengaard JR (2007). Growth hormone increases the proliferation of existing cardiac myocytes and the total number of cardiac myocytes in the rat heart. Cardiovasc Res 76:400-8.

Brüel A, Nyengaard JR (2005). Design-based stereological estimation of the total number of cardiac myocytes in histological sections. Basic Res Cardiol 100:311-9.

Brüel A, Nyengaard JR, Danielsen CC (2006). MMP-2 in the left rat ventricle is increased by growth hormone. Growth Horm IGF Res 16:193-201.

Brüel A, Oxlund H, Nyengaard JR (2002). Growth hormone increases the total number of myocyte nuclei in the left ventricle of adult rats. Growth Horm IGF Res 12:106-15.

Brüel A, Oxlund H, Nyengaard JR (2005). The total length of myocytes and capillaries, and total number of myocyte nuclei in the rat heart are time-dependently increased by growth hormone. Growth Horm IGF Res 15:256-64.

Gundersen HJG (1977). Notes on the estimation of numerical density of arbitrary profiles: the edge effect. J Microsc 111:219-23.

Gundersen HJG (1986). Stereology of arbitrary particles. A review of unbiased number and size estimators and the presentation of some new ones, in memory of Wiliam R. Thompson. J Microsc 143:3-45.

Gundersen HJG (2002). The smooth fractionator. J Microsc 207:191-210.

Jack EM, Bentley P, Bieri F, Muakkassah-Kelly SF, Stäubli W, Suter J, Waechter F, et al. (1990). Increase in hepatocyte and nuclear volume and decrease in the population of binucleated cells in preneoplastic foci of rat liver: a stereological study using the nucleator method. Hepatology 11:286-97. 
Kroustrup JP, Gundersen HJG (1983). Sampling problems in an heterogeneous organ: quantitation of relative and total volume of pancreatic islets by light microscopy. $\mathrm{J}$ Microsc 132:43-55.

Méndez J, Keys A (1960). Density and composition of mammalian muscle. Metabolism 9:184-8.

Nyengaard JR, Gundersen HJG (1992). The isector: a simple and direct method for generating isotropic, uniform random sections from small specimens. J Microsc 165:427-31.
Raya TE, Gaballa M, Anderson P, Goldman S (1997). Left ventricular function and remodeling after myocardial infarction in aging rats. Am J Physiol 273:H2652H2658.

Sterio DC (1984). The unbiased estimation of number and sizes of arbitrary particles using the disector. J Microsc 134:127-36.

Weibel ER (1979). Elementary introduction to stereological principles. Practical methods for biological morphometry. Academic Press. 